\title{
INDICAÇÕES OFICIAIS E RESULTADOS INICIAIS DA POLÍTICA DE AMPLIAÇÃO DO ENSINO FUNDAMENTAL
}

\author{
OFFICIAL INDICATIONS AND INITIAL RESULTS OF EXPANSION \\ OF FUNDAMENTAL EDUCATION POLICY
}

INDICACIONES OFICIALES Y RESULTADOS INICIALES DE LA
POLÍTICA DE AMPLIACIÓN DE LA ENSEÑANZA FUNDAMENTAL

JAQUELINE CRISTINA DA SILVA ${ }^{1}$

GÉssica PRISCILA Ramos ${ }^{1}$

Universidade Federal De São Carlos (UFSCar), São Carlos/SP - Brasil ${ }^{1}$

Resumo Há mais de 10 anos está em vigência, no Brasil, a Lei nº 11.274/06, que alterou a duração do ensino fundamental e antecipou o ingresso da criança no ensino fundamental. Assim, o objetivo deste artigo é relacionar os resultados das pesquisas sobre o ensino fundamental de nove anos, de 2010 a 2016, com o amparo oficial referente ao Programa Ampliação do Ensino Fundamental para Nove Anos no Brasil, tendo como procedimentos metodológicos a revisão bibliográfica e a pesquisa documental. Os dados obtidos levaram-nos a perceber que, apesar do amparo oficial, essa proposta de ampliação chegou às escolas sem uma efetiva preparação dos docentes e gestores, que, com base no imediatismo e espontaneísmo, e por meio de esforços individuais, têm feito o possível para conseguirem efetivar a mudança.

Palavras-chave: Ensino fundamental de nove anos; Estudo bibliográfico; Estudo docuMENTAL; ANÁLISE RELACIONAL.

Abstract For more than 10 years, Law $n^{\circ} .11 .274 / 06$, which changed the duration of fundamental education and anticipated the entry of the child into fundamental education. Thus, the objective of this article is to relate the results of nine-year fundamental education research, from 2010 to 2016, with the official support related to the Expansion of Fundamental 
Education Program for Nine Years in Brazil, having as methodological procedures the bibliographic review and the documentary research. The data obtained led us to realize that, despite the official support, this proposal of expansion reached schools without an effective preparation of teachers and managers, who, based on the immediatism and spontaneity, and through individual efforts, has done the change.

Keywords: Nine-year fundamental education; Bibliographic study; Documentary study; Relational analysis.

Resumen Hace más de 10 años está en vigencia, en Brasil, la Ley n ${ }^{\circ} 11.274$ / 06, que alteró la duración de la enseñanza fundamental y anticipó el ingreso del niño en la enseñanza fundamental. Así, el objetivo de este artículo es relacionar los resultados de las investigaciones sobre la enseñanza fundamental de nueve años, de 2010 a 2016, con el amparo oficial referente al Programa Ampliación de la Enseñanza Fundamental para Nueve Años en Brasil, teniendo como procedimientos metodológicos la revisión bibliográfica y la investigación documental. Los datos obtenidos nos llevaron a percibir que, a pesar del amparo oficial, esa propuesta de ampliación llegó a las escuelas sin una efectiva preparación de los docentes y gestores, que, con base en el inmediatez y espontaneísmo, y por medio de esfuerzos individuales, posible para lograr el cambio.

Palabras clave: Enseñanza fundamental de nueve años; Estudio bibliográfico; Estudio DOCUMENTAL; ANÁLISIS RELACIONAL.

\section{INTRODUÇÃo}

Em 2006, a educação brasileira passou por importante alteração com a ampliação do ensino fundamental para nove anos e a inserção da criança de 6 anos de idade nessa etapa. Tal mudança repercutiu não só no trabalho dos profissionais da educação, como também na escolarização das crianças, causando significativa consequência na organização legal, pedagógica e curricular da educação básica. Isso porque, a partir de então, todas as instituições de ensino fundamental, bem como, professores, diretores, coordenadores e outros profissionais da educação - mesmo de educação infantil, instituição responsável por receber as crianças de 6 anos de idade antes dessa mudança - deveriam repensar toda organização escolar que estava posta até então.

Diante disso, vimos a necessidade de estudar o ensino fundamental de nove anos, já que este impacta diretamente no cenário atual da educação brasileira. Para isso, definimos como objetivo deste trabalho relacionar os resultados das pesquisas sobre o ensino fundamental de nove anos, de 2010 a 2016, com o amparo oficial dado pelo Conselho Nacional de Educação/Conselho Educação Básica (CNE/CEB) referente ao Programa Ampliação do Ensino Fundamental para Nove Anos no Brasil, tendo em vista refletir acerca de seu processo de implementação.

Inicialmente, utilizamos a pesquisa documental como procedimento metodológico. Verificamos que foram emitidas duas leis, 11 pareceres e homologadas três resoluções pelo 
CNE/CEB, que hoje constituem parte do amparo oficial do Programa. São eles: Lei $\mathrm{n}^{\circ}$. 11.114/05 (BRASIL, 2005a); Parecer $n^{\circ} .24 / 04$ (BRASIL, 2004a); Parecer $n^{\circ} .6 / 05$ (BRASIL, 2005b); Parecer no. 18/05 (BRASIL, 2005c); Resolução nº. 3/05 (BRASIL, 2005d); Lei $n^{\circ}$. 11.274/06 (BRASIL, 2006a); Parecer $n^{\circ} .39 / 06$ (BRASIL, 2006b); Parecer nº. 41/06 (BRASIL, 2006c); Parecer no. 45/06 (BRASIL, 2006d); Parecer no. 5/07 (BRASIL, 2007a); Parecer $n^{\circ}$. 7/07 (BRASIL, 2007b); Parecer $n^{\circ}$. 4/08 (BRASIL, 2008); Parecer $n^{\circ} .22 / 09$ (BRASIL, 2009a); Resolução nº. 1/10 (BRASIL, 2010a); Parecer nº. 11/10 (BRASIL, 2010b); Resolução no . 7/10 (BRASIL, 2010c).

Posteriormente, realizamos pesquisa bibliográfica com vistas a buscarmos os resultados iniciais da implantação da referida política. Foram selecionados artigos publicados entre o período de 2010 a 2016 . O ano de 2010 foi escolhido por representar a data limite de ampliação do ensino fundamental para nove anos, o que significa que desde 2010 todas as escolas brasileiras funcionam de acordo com essa nova configuração. As bases de busca utilizadas foram: Portal de periódicos Capes/MEC, Scielo e Google Acadêmico. Para a busca, foi definida a string "ensino fundamental de nove anos" + "estudo de caso". Com isso, foram encontrados um total de 1.070 textos. Para chegarmos às principais pesquisas sobre os resultados iniciais da política, usamos os seguintes filtros: 1) leitura de títulos e palavras-chave, 2) leitura de resumos, 3) leitura de introduções e considerações finais. Assim, a quantidade de textos considerados para leitura integral foram 11, conforme a Tabela 1:

Tabela 1: Ano, título, autor, local e tipo de publicação das pesquisas selecionadas

\begin{tabular}{|c|c|c|c|c|}
\hline ANO & TítULO & AUTOR & LOCAL & TIPO \\
\hline 2011 & $\begin{array}{c}\text { O ingresso de crianças de 6 anos no } \\
\text { ensino fundamental: uma pesquisa em } \\
\text { Rondônia }\end{array}$ & $\begin{array}{c}\text { Flávia Pansini; } \\
\text { Aline Paula Ma- } \\
\text { rin }\end{array}$ & Rondônia-RO & Artigo \\
\hline 2011 & $\begin{array}{c}\text { Ensino fundamental de nove anos: re- } \\
\text { percussões da Lei no. 11.274/2006 na } \\
\text { proposta curricular da rede municipal } \\
\text { de ensino de Juiz de Fora }\end{array}$ & $\begin{array}{c}\text { Lilian Aparecida } \\
\text { Lima }\end{array}$ & $\begin{array}{c}\text { Juiz de Fora } \\
\text {-MG }\end{array}$ & Dissertação \\
\hline 2011 & $\begin{array}{c}\text { Ensino fundamental de nove anos no } \\
\text { município de São Paulo: um estudo de } \\
\text { caso }\end{array}$ & $\begin{array}{c}\text { Sylvie Bonifacio } \\
\text { Klein }\end{array}$ & São Paulo-SP & Dissertação \\
\hline 2012 & $\begin{array}{c}\text { Implementação de Políticas Públicas: } \\
\text { um estudo de caso sobre a ampliação do } \\
\text { ensino fundamental para nove anos no } \\
\text { município de São Bernardo do Campo }\end{array}$ & $\begin{array}{c}\text { Lara Gonzalez } \\
\text { Gil }\end{array}$ & São Bernardo \\
do Campo- SP & Dissertação \\
\hline \multirow{2}{*}{2013} & $\begin{array}{c}\text { Ensino fundamental de nove anos: am- } \\
\text { pliação ou absorção? A experiência do } \\
\text { município de Londrina }\end{array}$ & $\begin{array}{c}\text { Soraia Kfouri } \\
\text { Salerno; Alzeni } \\
\text { de Jesus Correia } \\
\text { Fulchini }\end{array}$ & Londrina -PR & Artigo \\
\hline $\begin{array}{c}\text { A supremacia da perspectiva associa- } \\
\text { cionista em práticas alfabetizadoras no } \\
1^{\circ} \text {. ano do ensino fundamental de nove } \\
\text { anos }\end{array}$ & $\begin{array}{c}\text { Gabriela Medei- } \\
\text { ros Nogueira; } \\
\text { Eliane Teresinha } \\
\text { Peres }\end{array}$ & Pelotas-RS & Artigo \\
\hline
\end{tabular}




\begin{tabular}{|c|c|c|c|c|}
\hline ANO & TÍTULO & AUTOR & LOCAL & TIPO \\
\hline 2013 & $\begin{array}{c}\text { Implantação da política do ensino fun- } \\
\text { damental de nove anos: um estudo com } \\
\text { grupos focais de professores }\end{array}$ & $\begin{array}{c}\text { Selma Ferreira } \\
\text { de Oliveira }\end{array}$ & Marília-SP & Tese \\
\hline 2015 & $\begin{array}{c}\text { O currículo do novo primeiro ano do } \\
\text { ensino fundamental e a participação } \\
\text { infantil: o que acontece em chamado de } \\
\text { "novo" sala de aula pode ser? }\end{array}$ & $\begin{array}{c}\text { Mere Abramowi- } \\
\text { cz; Viviane Apa- } \\
\text { recida Silva }\end{array}$ & Curitiba-PR & Artigo \\
\hline 2015 & $\begin{array}{c}\text { Ampliação do ensino fundamental na } \\
\text { região sul do Brasil: pontos e contra- } \\
\text { pontos da proposta curricular }\end{array}$ & $\begin{array}{c}\text { Zenilde Durli; } \\
\text { Marilda Pasqual } \\
\text { Schneider }\end{array}$ & $\begin{array}{c}\text { Região Sul do } \\
\text { Brasil }\end{array}$ & Artigo \\
\hline \multirow{2}{*}{2016} & $\begin{array}{c}\text { A implementação do ensino fundamen- } \\
\text { tal de nove anos na rede municipal de } \\
\text { ensino de São Paulo }\end{array}$ & $\begin{array}{c}\text { Rosangela Apa- } \\
\text { recida dos Reis } \\
\text { Machado }\end{array}$ & São Paulo-SP & Tese \\
\hline $\begin{array}{c}\text { Implantação do ensino fundamental de } \\
\text { tudo de duas experiências escolares no } \\
\text { município de Taubaté/SP }\end{array}$ & $\begin{array}{c}\text { Ebe Camargo } \\
\text { Pugliese }\end{array}$ & Município de \\
Taubaté-SP & Dissertação \\
\hline
\end{tabular}

Fonte: Produção das autoras.

Por fim, relacionamos o que encontramos nas pesquisas com o que achamos nas determinações constantes dos textos oficiais da política de ampliação do ensino fundamental, buscando estabelecer conexões entre o oficializado e a prática do ensino fundamental de nove anos nas escolas.

\section{A política nos textos do CNE/CEB}

A ampliação do ensino fundamental para nove anos ocorreu em dois momentos. Primeiro, com a Lei $n^{\circ}$. 11.114/05, que estabeleceu que a matrícula das crianças no ensino fundamental fosse feita aos 6 anos de idade (BRASIL, 2005a). Todavia, apesar de tal Lei incluir a criança de 6 anos no ensino fundamental, ela não definia a ampliação da duração dessa etapa. Posteriormente, a Lei $n^{\circ}$. 11.274/06 efetivamente dispôs sobre a duração de nove anos para o ensino fundamental com matrícula obrigatória a partir dos 6 anos de idade, definindo, também, que municípios, Estados e distrito federal teriam até o ano de 2010 para efetivar a alteração (BRASIL, 2006a).

Ambas as legislações geraram dúvidas nos sistemas educacionais, já que a partir delas as escolas foram obrigadas a se ajustar ao novo formato estabelecido. Tais dúvidas se configuraram como objeto de diversas resoluções e pareceres emitidos pelo $\mathrm{CNE} / \mathrm{CEB}$ entre 2004 e 2010, a fim de auxiliarem na implantação do novo ensino fundamental. Assim, foram emitidos 11 pareceres e homologadas três resoluções pelo CNE/CEB. Esse amparo legal foi uma das principais ações oficiais nesse percurso histórico, trazendo definições e orientações gerais acerca da implementação da referida política. 
Dessa forma, inicialmente, o ensino fundamental de nove anos, como dito, tornou-se obrigatório com a Lei $\mathrm{n}^{\circ}$. 11.274/06, que sancionou sua duração e definiu a matrícula obrigatória a partir dos 6 anos de idade. Nesse sentido, o Parecer no. 41/06 (BRASIL, 2006c) explicou que a matrícula da criança de 6 anos implicaria a ampliação prévia do ensino fundamental para nove anos. Então, a criança de 6 anos de idade só poderia ser matriculada no ensino fundamental de uma dada escola caso a instituição tivesse implantado o ensino fundamental de nove anos (BRASIL, 2006c).

Segundo o Parecer $n^{\circ} .7 / 07$ (BRASIL, 2007b), os sistemas de ensino não poderiam admitir a possibilidade de adaptação curricular do ensino fundamental de oito anos para o de nove anos; contudo, deveriam coexistir, num período de transição, tanto o ensino fundamental de oito, quanto o ensino fundamental de nove anos, já com um projeto político-pedagógico próprio. Por essa razão, os alunos que já se encontravam matriculados no ensino fundamental de oito anos não teriam direito ao ensino fundamental de nove anos (BRASIL, 2007b).

A nova nomenclatura e a faixa etária também foram assuntos focalizados. A respeito disso, a Resolução $n^{\circ} .3 / 05$ (BRASIL, 2005d) apresentou importantes definições: o ensino fundamental anos iniciais, com duração de cinco anos, abrangendo crianças de 6 a 10 anos de idade; o ensino fundamental anos finais, com duração de quatro anos, englobando crianças e adolescentes dos 11 aos 14 anos de idade.

A data de corte para o ingresso da criança de 6 anos foi indicada de forma vaga pelo Parecer $n^{\circ}$. 24/04 (BRASIL, 2004a) para o início do ano letivo. Já a Resolução no. 1/10 (BRASIL, 2010a) foi mais detalhista e orientou que, para o ingresso no $1^{\circ}$. ano, a criança deveria ter 6 anos de idade completos até o dia 31 de março no ano de sua matrícula. Também destacou que as crianças que completassem 6 anos após essa data deveriam ser matriculadas na pré-escola (BRASIL, 2010).

Em termos pedagógicos, o Parecer $\mathrm{n}^{\circ}$. 4/08 (BRASIL, 2008) indicou a necessidade da construção de um novo currículo e organização geral para o ensino fundamental. Nele, ficou evidente que o $1^{\circ}$ ano não se destinaria exclusivamente à alfabetização, mas às diferentes áreas do conhecimento. Também deixou claro que o $1^{\circ}$ ano não equivaleria ao antigo último ano da pré-escola, nem à antiga primeira série do ensino fundamental de oito anos, ressaltando que ele deveria desenvolver uma proposta pedagógica própria, com novas normas curriculares. Sobre a avaliação, o referido Parecer recomendou que fosse "processual, participativa, formativa, cumulativa e diagnóstica", com vistas ao redimensionamento da ação pedagógica (BRASIL, 2008, p. 2). Para tanto, seria essencial a criação "de instrumentos e procedimentos de observação, de acompanhamento contínuo, de registro e de reflexão permanente sobre o processo de ensino e de aprendizagem" (BRASIL, 2008, p. 2).

O projeto político-pedagógico (PPP), por sua vez, segundo o Parecer CNE/CEB 18/05 (BRASIL, 2005c) precisaria considerar as condições socioculturais e educacionais das crianças, bem como, contemplar, conforme o Parecer no. 22/09 (BRASIL, 2009a): "os objetivos a serem alcançados por meio do processo de ensino"; "as áreas do conhecimento"; a "matriz curricular definida pelos sistemas de ensino"; a "oferta equitativa de aprendizagens 
e consequente distribuição equitativa da carga horária entre os componentes curriculares"; "as diversas expressões da criança"; "os conteúdos a serem ensinados e aprendidos"; "as experiências de aprendizagem escolares a serem vividas pelos alunos"; e "os processos de avaliação que terminam por influir nos conteúdos e nos procedimentos selecionados nos diferentes graus da escolarização" (BRASIL, 2009a, p. 4).

Nesse contexto, o Parecer $n^{\circ}$. 45/06 (BRASIL, 2006d) reforçou que o professor dos anos iniciais deveria ter diploma de conclusão do Ensino Médio na modalidade Normal ou ser graduado em Pedagogia. Além disso, mencionou que seria de interesse pedagógico que apenas um professor atuasse por turma, justamente para que ocorresse o tratamento inter e multidisciplinar dos conteúdos (BRASIL, 2006d).

No tocante à questão curricular, somente em 2010, último ano que os sistemas de ensino tinham para implementar o ensino fundamental de nove anos, que a Resolução $n^{\circ} .7$ (BRASIL, 2010c) foi publicada, fixando as diretrizes curriculares nacionais para o ensino fundamental de nove anos. Essas diretrizes reuniram os princípios, os fundamentos e os procedimentos definidos pelo $\mathrm{MEC} / \mathrm{CNE} / \mathrm{CEB}$ no decorrer de todo o percurso do Programa Ampliação do Ensino Fundamental para Nove Anos. Nesse sentido, elas indicavam que se deveria: assegurar a todos os alunos o acesso aos conhecimentos, para efetivação de desenvolvimento e aprendizagens equiparáveis; considerar princípios éticos, políticos e estéticos; garantir um currículo que articulasse vivências e saberes dos alunos com os conhecimentos historicamente acumulados, contribuindo para a construção da identidade dos estudantes; formular o projeto político-pedagógico e elaborar o regimento escolar por meio de processos participativos relacionados à gestão democrática; e integrar os conhecimentos escolares no currículo, levando em consideração a diversidade social, econômica e cultural e a variedade de interesses e necessidades dos estudantes. Além disso, estabeleceu no artigo 15 que os componentes curriculares obrigatórios do Ensino Fundamental deveriam ser organizados por áreas de conhecimento, sendo: Linguagens (Língua Portuguesa; Língua Materna, para populações indígenas; Língua Estrangeira Moderna; Arte; e Educação Física); Matemática; Ciências da Natureza; Ciências Humanas (História; Geografia); Ensino Religioso (BRASIL, 2010c, p. 4).

A mesma Resolução (BRASIL, 2010c) também esclareceu que caberiam apenas as funções normativas e de supervisão ao Conselho Nacional de Educação (CNE). Portanto, ficou sob responsabilidade dos Estados e municípios a elaboração de normas e orientações gerais com relação à reorganização administrativa e pedagógica, a adequação e aquisição dos materiais didáticos, o redimensionamento da educação infantil, entre outras coisas, como: "os recursos necessários à ampliação dos tempos e espaços", a formação continuada dos docentes e demais profissionais, "a coordenação do processo de implementação do currículo" e o "acompanhamento e a avaliação dos programas e ações educativas", bem como o "suprimento das necessidades detectadas" (BRASIL, 2010c, p. 14).

Dessa forma, vemos que a preocupação maior das legislações pesquisadas foi com as questões de ordem legal e administrativa, de modo que, as principais definições acerca da operacionalização cotidiana do ensino fundamental de nove anos se delimitaram sobre 
assertivas ou orientações genéricas, já que ficaram sob responsabilidade de Estados e municípios.

\section{Resultados INICIAIS da IMPLEMENTAÇ̃̃o da POLÍTICA NAS PESQUiSAS}

Várias são as pesquisas voltadas ao estudo da política de ampliação do ensino fundamental para nove anos no Brasil. Todavia, durante o levantamento bibliográfico, focamos aquelas que se voltaram especificamente para a compreensão dos efeitos e resultados do ensino fundamental de nove anos nas escolas. Nesse caso, encontramos 11 textos, que serão apresentados a seguir.

$\mathrm{O}$ artigo " $\mathrm{O}$ ingresso de crianças de 6 anos no ensino fundamental: uma pesquisa em Rondônia" (PANSINI; MARIN, 2011) teve o objetivo de analisar como as determinações legais sobre a ampliação do ensino fundamental para nove anos se materializaram em algumas escolas do Estado de Rondônia. De acordo com as autoras, a alteração no Estado foi decidida em 2006 no período de férias escolares, sem qualquer diálogo com os profissionais da educação (PANSINI; MARIN, 2011). Sendo que fatores importantes foram desconsiderados no momento da ampliação, como: a necessidade de planejamento para adaptações curriculares e de formação para os professores e o fato de que as escolas não estavam preparadas para realizar mudanças no espaço físico.

Pansini e Marin (2011) também relataram que apenas no final do ano de 2008 é que as escolas receberam uma mobília adaptada para as crianças de 6 anos de idade. Mesmo assim, segundo as autoras, os tamanhos das salas de aula impossibilitaram que as carteiras fossem organizadas em grupos e, consequentemente, acabaram por ser organizadas em fileiras, como na antiga $1^{\mathrm{a}}$ série.

Já a dissertação intitulada "Ensino fundamental de nove anos: repercussões da Lei $\mathrm{n}^{\mathrm{o}}$. 11.274/06 na proposta curricular da rede municipal de ensino de Juiz de Fora" (LIMA, 2011) objetivou investigar como a Lei $\mathrm{n}^{\circ}$. $11.274 / 06$ se disseminou na rede municipal de ensino da cidade de Juiz de Fora (MG), especificamente no que tange à proposta curricular. Segundo Lima (2011), o ensino fundamental de nove anos se tornou obrigatório no Estado de Minas Gerais já em 2003.

Um dos aspectos destacados foi em relação à data corte de ingresso da criança de 6 anos de idade. De acordo com Lima (2011), até o ano de 2009 não havia se estabelecido uma unanimidade na definição da data corte para a matrícula da criança. Como resultado disso, a autora destaca que, em uma turma de $1^{\circ}$. ano, era possível encontrar crianças de 5 , 6 e 7 anos. Além disso, a limitação e inadequação do espaço das escolas (ausência de espaço físico, de parquinhos e de brinquedotecas) para receber as crianças de 6 anos também foram itens evidenciados por Lima (2011).

Lima (2011) também apresenta discussões sobre o currículo do ensino fundamental de nove anos, que por falta de uma preparação prévia precisou ser apenas adaptado dos outros anos. A autora constatou que a escola investigada tomava como base o que já era trabalhado no último ano da educação infantil, apenas ajustando para as turmas iniciantes no ensino fun- 
damental. Isso porque, apesar de a ampliação ser obrigatória desde 2004 no município, a reorganização curricular só estava sendo realizada naquele momento, em 2010 (LIMA, 2011).

$\mathrm{Na}$ dissertação "Ensino fundamental de nove anos no município de São Paulo: um estudo de caso" (KLEIN, 2011), o objetivo foi analisar possíveis relações entre o amparo legal e o cotidiano escolar de um $1^{\circ}$ ano do ensino fundamental de nove anos no decorrer da implementação da política de ampliação. Uma primeira verificação de Klein (2011) foi com relação à nomenclatura. De acordo com a autora, ainda que o ensino fundamental de nove anos já estivesse em fase de implantação, as turmas ingressantes continuavam sendo chamadas de $1^{\text {a }}$ série (e não $1^{\mathrm{o}}$ ano), bem como, as outras turmas, de $2^{\mathrm{a}}$ série e assim por diante.

Outro aspecto abordado por Klein (2011) diz respeito à adequação dos espaços físicos e materiais. Apesar de toda orientação oficial nacional enfatizar a necessidade de adequar a infraestrutura e os materiais para receber as crianças de 6 anos de idade, Klein (2011) comprovou que a escola não estava preparada para isso. A autora destaca que houve críticas tanto ao mobiliário das salas de aula, quanto aos outros espaços da escola. No entanto, os profissionais entrevistados também ressaltaram o esforço da escola em conseguir fazer algumas adaptações (KLEIN, 2011).

Além disso, como a maior parte das tarefas - voltadas à implantação da política ficaram sob responsabilidade dos professores, para Klein (2011), a formação continuada deles se tornava essencialmente relevante dentro da proposta. Conforme a autora, no Projeto Municipal de Implantação de São Paulo a formação estava prevista, mas não ocorreu de acordo com o que foi inicialmente proposto. Mesmo assim, foram constatadas falas elogiando os cursos de formação continuada e muitas professoras os tinham como uma importante referência. Outras, no entanto, defendiam opiniões diferentes, mas ainda assim os consideravam importantes (KLEIN, 2011).

A respeito do processo de implementação, a própria coordenadora pedagógica chegou a admitir que nem todas as dúvidas dos profissionais haviam sido esclarecidas (KLEIN, 2011). Um dos questionamentos que ficaram sem resposta, conforme Klein (2011), foi com relação ao $1^{\circ}$ ano e o que ele deveria ser exatamente. Entre as diferentes posições dos professores e gestores, a escola acabou fazendo aquilo que considerava mais adequado.

Em relação às atividades propostas às crianças, Klein (2011) observou que os principais exercícios envolviam a alfabetização ou outras atividades diferenciadas, mas que exigiam longos períodos de concentração por parte das crianças. Assim, pouco espaço foi destinado para trabalhar as outras linguagens e áreas do conhecimento. Além disso, Klein (2011) constatou que o espaço do parque também não era usado diariamente e que nem mesmo havia um período específico destinado a sua utilização. Entretanto, a autora destaca que, no final do semestre, algumas mudanças começaram a aparecer na prática dos professores, o que ela acredita ser resultado da formação continuada.

Ademais, Klein (2011) conclui enfatizando que a alfabetização era a grande meta da escola. A autora ressalta, ainda, que, apesar de outras atividades (músicas, jogos, brincadeiras) terem sido inseridas na prática pedagógica, o foco nunca deixou de ser a alfabetização. Destarte, para Klein (2011), a inserção dessas atividades diferenciadas no ensino 
fundamental de nove anos se afasta "da perspectiva adotada pelas pedagogias da infância", aproximando-se mais de "teorias que vêem no jogo um recurso didático da aprendizagem" (KLEIN, 2011, p. 198).

Já na dissertação intitulada "Implementação de Políticas Públicas: um estudo de caso sobre a ampliação do ensino fundamental para nove anos no município de São Bernardo do Campo" (GIL, 2012), de 2012, o objetivo foi analisar a ampliação do ensino fundamental para nove anos no município de São Bernardo do Campo (SP). O primeiro aspecto analisado pela autora foi com relação à atribuição e formação de professores. Gil (2012) relata que um dos critérios utilizados pela direção da escola para atribuir turmas de $1^{\circ}$ ano aos professores foi, justamente, ter trabalhado com educação infantil em algum momento anterior, ou ainda, com alfabetização. Apesar disso, em momento algum as professoras e a diretora afirmaram ter lido ou discutido o material referente à política de ampliação do ensino fundamental para nove anos (GIL, 2012).

O segundo item discutido pela autora foi o currículo do ensino fundamental de nove anos. Gil (2012) enfatiza que, inicialmente, a preocupação era em não se restringir a aprendizagem do $1^{\circ}$ ano à alfabetização, mas também garantir momentos para o brincar. Contudo, no Projeto Político-Pedagógico da escola constavam objetivos e conteúdos que seriam trabalhados em todas as turmas de ensino fundamental, sendo que os do $1^{\circ}$ ano estavam organizados por áreas de conhecimento e não incluía o brincar.

Outro aspecto discutido por Gil (2012) foi a rotina e o espaço físico do $1^{\circ}$ ano do ensino fundamental de nove anos. Segundo a autora, no primeiro semestre de observação as crianças tinham espaço no pátio da escola para brincar, dançar e cantar às sextas-feiras. Entretanto, no segundo semestre, quando as pesquisadoras não faziam mais observações para a pesquisa, as professoras já não garantiam o brincar com tanta frequência e não souberam justificar o porquê dessa mudança de atitude. Nesse mesmo sentido, Gil (2012) afirma que também houve uma diminuição do uso do parque, o que, para ela, demonstra que a preocupação com o brincar foi diminuindo com o passar do tempo, tornando o $1^{\circ}$ ano mais próximo da antiga $1^{\mathrm{a}}$ série. Aliás, Gil (2012) observou outros aspectos em relação à rotina e ao espaço físico. Conforme a autora:

[...] não houve, por parte da Secretaria de Educação do Município, uma preocupação com a compra de mesas e cadeiras novas para as crianças de seis anos, cabendo à diretora da escola planejar e realocar as mesas e cadeiras da escola, quando chegaram outras para as crianças menores (GIL, 2012, p. 88).

Além disso, Gil (2012) atentou para o fato de que a disposição da sala de aula mostrava preocupação maior com relação à alfabetização, em detrimento do brincar. Isso porque, conforme a autora, havia uma predominância de cartazes relacionados aos sistemas de escrita e numérico, enquanto que os livros, brinquedos e outros materiais lúdicos ficavam todos fora do alcance das crianças.

Sobre a avaliação de aprendizagem, Gil (2012) salienta que existiam fichas de avaliação individual, em que constavam os objetivos específicos de cada área de conhecimento. 
A professora deveria anotar se o aluno tinha ou não obtido rendimento satisfatório em cada uma delas. Esse tipo de avaliação, para obter o rendimento dos alunos, foi questionado pelas professoras em uma reunião do Conselho.

Apesar de as professoras terem sugerido essa mudança na avaliação, Gil (2012) observou que, no segundo semestre, continuaram usando as fichas de avaliação individual ao invés de utilizarem um relatório individual sobre cada criança.

Por fim, a autora conclui que os resultados que obteve na pesquisa de campo demonstraram que os professores, gestores e pais entrevistados não tinham consenso sobre a ampliação do ensino fundamental para nove anos e, ainda, que a proposta não parecia ter sido discutida, tanto que alguns não possuíam nem mesmo conhecimento das mudanças.

Outro artigo analisado foi o "Ensino fundamental de nove anos: ampliação ou absorção? A experiência do município de Londrina" (SOLERNO; FULCHINI, 2013), de 2013. Ele teve como objetivo identificar as adequações pedagógicas na matriz curricular das escolas municipais de Londrina (PR) que tinham se organizado para receber a criança de 6 anos de idade (SOLERNO; FULCHINI, 2013, p. 58). O que Solerno e Fulchini (2013) constataram foi que a idade das crianças ingressantes, 6 anos, era considerada um dos principais obstáculos para o ensino fundamental de nove anos, pois seriam crianças imaturas e totalmente dependentes. $\mathrm{O}$ aspecto da estrutura física também foi um ponto destacado como precário pelos professores, que acreditavam que a falta de um espaço adequado poderia comprometer a brincadeira, considerada algo importante para a criança.

Sobre a questão do planejamento, Solerno e Fulchini (2013) destacam que não havia definição clara do que seria trabalhado com as crianças e como. Já em relação à formação continuada, as professoras participantes da pesquisa afirmaram que discutiam, com frequência, apenas o conteúdo de matemática, português e letramento. Apesar disso, Solerno e Fulchini (2013) concluem dizendo que:

[...] o Sistema Municipal de Londrina iniciou o ensino de nove anos sem pre-
paração e criação das condições indispensáveis para assegurar o atendimento
das especificidades da criança de seis anos. Evidenciou também a inexistência
de um projeto de educação por parte da Secretaria Municipal de Educação no
que tange a uma proposta clara para trabalhar principalmente com o primeiro
ano, sala em que são inseridas as crianças dessa faixa etária (SOLERNO, FUL-
CHINI, 2013, p. 69).

Já o artigo "A supremacia da perspectiva associacionista em práticas alfabetizadoras no $1^{\circ}$ ano do ensino fundamental de nove anos" (NOGUEIRA; PERES, 2013), de 2013, aponta como objetivo analisar a prática de alfabetização e letramento em uma turma de $1^{\circ}$ ano do ensino fundamental de nove anos, na cidade de Pelotas (RS), em 2010. As autoras se debruçaram em analisar as atividades desenvolvidas nos cadernos das crianças e puderam perceber a ênfase no ensino da Língua Portuguesa, que era realizado como uma sequência gradativa de conteúdos (vogais, consoantes, sílabas e palavras). Conforme as autoras: "Essa forma de organização indica uma perspectiva de alfabetização que supõe uma 'gradação de 
dificuldades': das letras às palavras e somente no 'final' do processo de alfabetização o contato com os textos" (NOGUEIRA; PERES, 2013, p. 76-77). Para Nogueira e Peres (2013), esse modelo encontrado nos cadernos mostra uma proposta tradicional de alfabetização, mesmo que o curso de formação continuada de professores tenha indicado outra perspectiva de alfabetização, que englobasse práticas sociais e usos cotidianos da escrita. Inclusive, durante toda a pesquisa, elas não constataram atividade alguma que envolvesse a escrita espontânea por parte das crianças, e, ainda, perceberam a ausência total de atividades de língua escrita, sendo que a maioria das atividades se traduzia em cópia de letras, sílabas, palavras, pequenas frases e escritas mecânicas (NOGUEIRA; PERES, 2013).

A tese de doutorado intitulada "Implantação da política do ensino fundamental de nove anos: um estudo com grupos focais de professores" (OLIVEIRA, 2013), de 2013, teve como objetivo analisar a percepção dos professores dos anos iniciais do ensino fundamental no município de Marília (SP). Uma primeira análise foi com relação à estrutura física das escolas. Para os professores entrevistados, a ideia do MEC de priorização do lúdico no processo de ensino e aprendizagem era incompatível com a estrutura física das escolas (OLIVEIRA, 2013). Outro aspecto apontado diz respeito à alfabetização e avaliação da criança, apesar de Oliveira (2013) considerar que o aprendizado da leitura e escrita deveria ocorrer por meio de atividades lúdicas, a forma de avaliação de aprendizagem solicitada pelo município acabava sendo incompatível com uma aprendizagem pautada no lúdico, já que se tratava de uma avaliação formal e sistemática, que visava indicar quem estava alfabetizado ou não.

Em relação às novidades e diferenças constatadas pelos professores no ensino fundamental de nove anos, Oliveira (2013) evidencia diferentes tipos de discursos. Uns apontavam que havia ocorrido mudanças profundas, inclusive em sua própria prática, enquanto outros mencionavam não ter percebido qualquer tipo de mudança efetiva. Aqueles que afirmavam haver mudança perceberam que o ensino fundamental de nove anos exigia uma alteração na didática, especialmente em relação à inclusão do lúdico. Outros professores, ainda, negaram a existência de mudanças, especialmente pela questão do espaço físico e da falta de materiais compatíveis com as crianças de 6 anos de idade (OLIVEIRA, 2013).

Oliveira (2013) constatou que o aspecto do espaço físico foi mencionado por quase metade dos docentes como importante para a promoção de um ensino de qualidade. Além desse item, os recursos humanos existentes na escola também foram considerados insuficientes. Alguns professores destacaram, também, a necessidade de profissionais mais capacitados e em maior número para colaborar com a melhoria de qualidade do ensino.

Nessa direção, Oliveira (2013) menciona o fato de que a lista de indicações sugeridas pelos professores era bem extensa, mas que, quando os questionou sobre qual era a relação existente entre os materiais, espaços, formação e os avanços diretos na aprendizagem do aluno, as discussões foram amenas e se resumiam a aspectos estruturais e materiais.

Em 2015, foi publicado o artigo "O currículo do novo primeiro ano do ensino fundamental e a participação infantil: o que acontece em sala de aula pode ser chamado de 'novo'?" (ABRAMOWICZ; SILVA, 2015), em que as autoras buscaram responder às se- 
guintes questões: 1) Os professores estariam preparados para o "novo" currículo do ensino fundamental de nove anos? 2) Quais seriam as implicações diretamente relacionadas às salas de aula? Para isso, realizaram a investigação em uma turma de $1^{\circ}$ ano de uma escola pública de Curitiba (PR). Foi constatado que, além de não ter existido uma preparação dos profissionais, também não havia ocorrido muitas mudanças práticas para além da alteração da nomenclatura. Assim, o ensino fundamental de nove anos continuava com as mesmas características que o de oito anos, e a criança, tão mencionada nos materiais do MEC, não estava sendo respeitada "em sua peculiar forma de aprender movimentando-se, investigando, experimentando e falando. A ela são dadas ordens de silêncio, imobilidade e obediência" (ABRAMOWICZ; SILVA, 2015, p. 539).

Além de não terem percebido mudanças efetivas nas práticas pedagógicas dos professores, Abramowicz e Silva (2015) identificaram, nas falas das professoras, uma concepção inferiorizada da criança. Nos depoimentos recolhidos, as crianças eram sempre definidas como ingênuas, dependentes e desinteressadas.

Outra observação destacada pelas autoras foi que as crianças eram submetidas a atividades mecânicas de alfabetização e matemática e, mesmo nas aulas de Artes, Educação Física e Músicas, eram obrigadas a ficar sentadas. Abramowicz e Silva (2015) também notaram que o brincar não foi levado em consideração como uma linguagem da infância no caso estudado. Para aquelas professoras entrevistadas, brincar e aprender eram coisas separadas e, por isso, inclusive, muitas vezes o brincar era proibido por elas (ABRAMOWICZ; SILVA, 2015).

Por sua vez, o artigo "Ampliação do ensino fundamental na Região Sul do Brasil: pontos e contrapontos da proposta curricular" (DURLI; SCHNEIDER, 2015), também de 2015 , teve como objetivo refletir sobre as demandas curriculares das escolas de educação básica em decorrência da ampliação da duração do ensino fundamental. O estudo foi desenvolvido em escolas estaduais da região sul do Brasil (Paraná, Santa Catarina e Rio Grande do Sul). De acordo com o texto, a Secretaria Estadual de Educação do Rio Grande do Sul só tomou iniciativas mais abrangentes com relação à implementação do ensino fundamental de nove anos em 2011, sendo que uma das preocupações era a adaptação das escolas para receber a nova faixa etária ingressante, já que era indicada a importância da brincadeira e dos brinquedos como ferramentas pedagógicas (DURLI; SCHNEIDER, 2015).

Com relação à revisão curricular no novo ensino fundamental, as autoras Durli e Schneider (2015) perceberam a escassa participação dos professores nesse processo, o que pode ter colaborado para dificultar o delineamento da proposta de ampliação. As autoras mencionam, ainda, que algumas escolas terceirizaram essa tarefa.

Assim, conforme relatado por Durli e Schneider (2015), como forma de "garantir o sucesso" naquele momento, as escolas estabeleceram parcerias com empresas, abrindo mão de decidirem sobre questões pedagógicas e curriculares. Ressaltam que, posteriormente, houve algumas iniciativas voltadas para a formação continuada de professores, mas que, no geral, o professor foi excluído de pensar o processo pedagógico.

$\mathrm{Na}$ tese intitulada "A implementação do ensino fundamental de nove anos na rede municipal de ensino de São Paulo" (MACHADO, 2016), de 2016, o objetivo foi compre- 
ender os processos de implementação do ensino fundamental no município de São Paulo (SP). A pesquisa de campo foi realizada por meio de entrevistas com professores dos anos iniciais e gestores. Ao descrever os espaços da escola em que a pesquisa foi desenvolvida, Machado (2016) menciona a existência de uma quadra poliesportiva e outra área reservada para atividades diversas, onde foram instalados balanços e escorregadores após a implantação do ensino fundamental de nove anos. Além disso, outro espaço, que até então ficava ocioso, foi transformado em brinquedoteca. Entretanto, não houve, inicialmente, adaptação dos móveis, inclusive, as carteiras existentes naquele momento eram grandes demais para as crianças ingressantes (MACHADO, 2016).

Conforme Machado (2016), professoras mostraram sentir-se despreparadas e desorientadas para lidar com as crianças de 6 anos de idade. Além disso, também observou não existir brincadeira como parte da rotina. Algumas professoras separavam um dia da semana para isso, sendo que cada professora era livre para organizar essa questão conforme suas concepções e da maneira que achasse melhor. Aliás, uma das professoras entrevistadas chegou a afirmar que o lúdico não estava sendo utilizado no ensino fundamental de nove anos (MACHADO, 2016).

$\mathrm{Na}$ dissertação "Implantação do ensino fundamental de nove anos e mudança educacional: estudo de duas experiências no município de Taubaté/SP" (PUGLIESE, 2016), de 2016, o objetivo foi investigar o processo de implantação da política de ampliação do ensino fundamental para nove anos no município de Taubaté. A pesquisa foi realizada em duas escolas municipais e envolveu entrevistas semiestruturadas com os diretores e coordenadores. Um primeiro aspecto observado foi a introdução da política de ampliação do ensino fundamental nas escolas. Pugliese (2016) destaca não ter havido debate ou discussões sobre a nova configuração do ensino fundamental e que a chegada da legislação não foi acompanhada de outras mudanças, nem de espaço, nem de materiais, então, o $1^{\circ}$ ano nada mais era do que a antiga $1^{\text {a }}$ série, inclusive em conteúdos.

Outro item destacado pela autora diz respeito ao treinamento externo dos professores para lidar com as mudanças do ensino fundamental. Segundo Pugliese (2016), a coordenação pedagógica demonstrava em seus depoimentos uma concepção empresarial de formação continuada, já que, na localidade, uma empresa tinha ficado responsável pela "capacitação" dos professores a partir de um sistema apostilado de ensino. Isso revela, para a autora, que a preparação dos professores não foi pensada e realizada no interior das escolas, em conjunto com o coletivo, mas foi fruto de um treinamento externo, contratado. Pugliese (2016) também observou que as professoras não tiveram contato com os materiais do MEC e, ainda, que quem recebia as informações oficiais era o diretor que ficava encarregado de repassar para o restante dos profissionais da escola. Com isso, Pugliese (2016) afirma que, na prática: "a adoção de compromissos coletivos verdadeiramente participativos não se efetivou" (PUGLIESE, 2016, p. 106).

Em relação à política traduzida em práticas educativas, Pugliese (2016) constatou que as principais mudanças que se efetivaram partiram de esforços individualizados e isolados de cada professor, que acabou fazendo do jeito que achava mais adequado. Segundo 
a autora, não houve uma integração entre os profissionais da rede de ensino e mudanças profundas nas práticas, apenas "acomodações aligeiradas" (PUGLIESE, 2016, p. 114). Foi relatada, pelos docentes, a carência de discussões sobre os documentos, o currículo e o processo de implantação em si.

Dessa maneira, apresentamos brevemente o quadro de pesquisas e os principais resultados sobre a prática do ensino fundamental de nove anos, publicadas entre os anos de 2010 e 2016. Apesar de as pesquisas terem sido realizadas em diferentes regiões do país, ficou evidente que, não obstante a referida política ter chegado às escolas brasileiras com um objetivo pronto, o de ampliação da duração do ensino fundamental em nove anos, sua chegada se deu de maneira bastante nebulosa. O que verificamos com a leitura dessas 11 pesquisas foi que, independente do município ou do Estado em que as investigações foram realizadas, os problemas encontrados pelos pesquisadores foram praticamente os mesmos: falta de preparação dos profissionais, falta de recursos para a adaptação dos ambientes e materiais, falta de informações precisas.

\section{ENTRE O OFICIAL E A PRÁtica}

Após analisarmos o amparo legal identificando as principais definições acerca da política de ampliação da duração do ensino fundamental para nove anos, e também, após realizarmos a leitura e discussão das pesquisas referentes à implementação e à prática dessa proposta, é possível estabelecermos algumas relações entre elas.

Um dos aspectos mencionados em mais da metade das pesquisas encontradas na revisão bibliográfica foi em relação ao espaço físico e material das escolas, especialmente para receber as crianças de 6 anos de idade. Sobre isso, o Parecer no. 22/09 (BRASIL, 2009a) deixa claro que seria de responsabilidade dos Conselhos Estaduais e Municipais de Educação criar espaços apropriados e materiais didáticos compatíveis com o desenvolvimento da criança. Nesse mesmo sentido, a Resolução nº 7/10 (BRASIL, 2010c) também destaca que caberiam às redes de ensino prover "os recursos necessários à ampliação dos tempos e espaços dedicados ao trabalho educativo nas escolas e a distribuição de materiais didáticos e escolares adequados" (BRASIL, 2010c, p. 14).

O que as pesquisas apontaram, em geral, é que não houve uma verdadeira mudança na organização espacial e dos materiais escolares. Algumas pesquisas também demonstraram que, mesmo quando havia tido algum tipo de adaptação, como a construção de parque ou brinquedoteca, os lugares não eram utilizados como parte da rotina escolar.

Pansini e Marin (2011), por exemplo, enfatizaram que as escolas que participaram de sua investigação não estavam preparadas para fazer mudanças no espaço físico nem para realizar adaptações curriculares. Lima (2011) e Klein (2011) também encontraram dados parecidos, em que os entrevistados destacaram que a escola não estava, fisicamente e materialmente, preparada para receber as crianças de 6 anos de idade. Solerno e Fulchini (2013) e Oliveira (2013) igualmente observaram nas falas das professoras a precariedade 
da estrutura física das escolas, o que, para as entrevistadas, comprometia a brincadeira e inviabilizava o lúdico no processo de ensino e aprendizagem.

Gil (2012) foi uma das pesquisadoras que notaram um comportamento um pouco diferente, mesmo que no curto espaço de um semestre. A autora relata que presenciou momentos em que as crianças podiam brincar livremente pelo pátio da escola, mas que, no segundo semestre, essa prática diminuiu drasticamente. Machado (2016) também destacou uma experiência, aparentemente, diferente. A autora constatou que houve um investimento no espaço físico, com a colocação de balanços e escorregadores e a criação de uma brinquedoteca. Todavia, as carteiras e o banheiro não foram adaptados para receber as crianças, que ficavam pequenas demais perto das mobílias existentes.

Outro item que ganhou destaque nas pesquisas analisadas diz respeito ao currículo do ensino fundamental de nove anos. O Parecer $n^{\circ}$. 4/08 (BRASIL, 2008) evidencia que o ensino fundamental de nove anos deveria ter novo caráter, com propostas próprias. Inclusive, destaca que o $1^{\mathrm{o}}$ ano não deveria ser confundido com a antiga $1^{\mathrm{a}}$ série, tampouco com o último ano da pré-escola.

Na pesquisa de Lima (2011), esse fato apareceu como um impasse na escola pesquisada. Conforme a autora, por falta de esclarecimento, a escola tomava como base o que já era trabalhado no último ano da educação infantil, apenas se adaptando para as turmas iniciantes no ensino fundamental. Klein (2011) também constatou que o fato de a legislação ter mencionado que o $1^{\mathrm{o}}$ ano não seria a antiga $1^{\mathrm{a}}$ série nem o último ano da pré-escola não resolveu a dúvida dos professores sobre o que ele seria exatamente. Como consequência da falta de definição, a escola acabou agindo segundo achava mais adequado. Na pesquisa de Pugliese (2016), inclusive, uma das professoras chegou a afirmar que os conteúdos do $1^{\circ}$ ano eram os mesmos do que os da antiga $1^{\mathrm{a}}$ série.

Ainda sobre a questão curricular, o mesmo Parecer (BRASIL, 2008) também enfatiza que os três primeiros anos não deveriam ser exclusivos para o ensino de alfabetização, mas que deveria ser garantido, pelos professores, o desenvolvimento das diversas expressões e áreas do conhecimento. Além disso, a Resolução nº. 7/10 (BRASIL, 2010c) destaca que o currículo precisaria buscar articular os saberes que vêm dos alunos com os conhecimentos historicamente acumulados.

Apesar dessa orientação, Klein (2011) observou que os principais exercícios ofertados às crianças de 6 anos de idade envolviam a alfabetização ou outras atividades de concentração. Não houve, portanto, espaço destinado ao desenvolvimento de outras linguagens e áreas do conhecimento. Gil (2012), Solerno e Fulchini (2013), Oliveira (2013) e Abramowicz e Silva (2015) também notaram a forte presença da alfabetização em detrimento de outras linguagens, como o brincar. Para Gil (2012), na escola investigada, essa questão contribui para uma aproximação do $1^{\circ}$ ano com os outros anos do ensino fundamental. Nogueira e Peres (2013) também verificaram a questão da alfabetização em sua investigação. Conforme as autoras, além do ensino de Língua Portuguesa ser o mais evidente, era lecionado como nas antigas $1^{\text {as }}$ séries: primeiro trabalhavam com vogais, depois consoantes, sílabas, palavras, frases e, só depois, textos. 
Por esse caminho, vemos que o brincar, uma das formas de expressão da criança, foi negligenciado nos currículos das escolas. Gil (2012), Oliveira (2013) e Machado (2016) perceberam o distanciamento do brincar no currículo, já que esse nem mesmo fazia parte da rotina das crianças. Abramowicz e Silva (2015), além de verificarem que as crianças eram submetidas a atividades mecânicas, independente da área de conhecimento, notaram que o brincar não foi considerado como linguagem da infância e, por isso, brincar e aprender estavam separados.

A formação continuada dos professores também fazia parte da política de ampliação do ensino fundamental para nove anos e, aliás, também foi um dos pontos discutidos em boa parte do material analisado. Conforme a Resolução no . 7/10 (BRASIL, 2010c), a preparação dos profissionais da escola para a implementação da política seria de total responsabilidade dos sistemas e redes de ensino, de modo que, não foram estabelecidos efetivos parâmetros para isso.

Como resultado, as pesquisas selecionadas mostram, em sua maioria, a insatisfação dos professores com relação à preparação para o ensino fundamental de nove anos e a recepção das crianças de 6 anos de idade. Pansini e Marin (2011) perceberam uma formação, mas fragmentada, e que só ocorreu quando as crianças de 6 anos de idade já estavam matriculadas. Gil (2012) verificou que as professoras entrevistadas nem mesmo tinham lido ou discutido o material oficial referente à ampliação. Klein (2011) encontrou opiniões diferentes: professoras que elogiavam o curso de formação continuada que receberam, e professoras que não viam colaborações efetivas para a prática. Machado (2016) observou que, apesar de ter existido uma preparação dos professores, eles mesmos afirmavam que as teorias estudadas não eram colocadas em prática no cotidiano.

Durli e Schneider (2015) e Pugliese (2016), por esse mesmo caminho, também notaram que a formação continuada não solucionou as questões dos professores, que acabaram colocando em prática aquilo que, individualmente, acreditavam ser o ideal. Mas, além disso, nas escolas envolvidas nessas pesquisas, a formação dos profissionais foi terceirizada, ou seja, a responsabilidade da preparação dos profissionais da escola foi transferida e pensada por uma empresa externa.

Além desses aspectos, a avaliação de desempenho, que sofreu modificações com a proposta de ampliação do ensino fundamental de nove anos, também foi citada em algumas pesquisas. Lima (2011), por exemplo, observou a realização de uma avaliação que tinha como objetivo averiguar a evolução dos conhecimentos de alfabetização dos alunos. Nesse mesmo sentido, Gil (2012) constatou a presença de fichas de avaliação individual, que visavam verificar o rendimento dos alunos em cada área do conhecimento.

Conforme o Parecer $n^{\circ} .4 / 08$, a avaliação deveria ser processual, participativa, formativa, cumulativa e diagnóstica. Ela não poderia se limitar a considerar resultados finais das crianças, nem mesmo classificá-las ou classificar seus conhecimentos. Desse modo, fica claro que a forma de avaliação evidenciada pelos pesquisadores (LIMA, 2011; GIL, 2012) vai de encontro com as orientações oficiais referente ao ensino fundamental de nove anos. 
Também foi constatada uma divergência entre os documentos e a prática quanto à nova nomenclatura do ensino fundamental. Uma das modificações da nomenclatura do ensino fundamental pressupunha que, se no ensino fundamental de oito anos existiam oito séries, no ensino fundamental de nove anos, conforme a Resolução no ${ }^{\circ}$ 3/05 (BRASIL, 2005d), passaram a existir nove anos. Apesar disso, Klein (2011) notou que na escola em que ocorreu sua investigação, ainda que o ensino fundamental de nove anos já estivesse funcionando, os profissionais continuavam chamando as turmas ingressantes de $1^{\mathrm{a}}$ série. Mesmo as outras turmas eram chamadas de $2^{\mathrm{a}}$ série, $3^{\mathrm{a}}$ série etc.

Outro item que também causou confusão diz respeito à data corte de entrada da criança de 6 anos de idade. Essa confusão se deu porque o Parecer no ${ }^{\circ}$ 24/04 (BRASIL, 2004a) havia indicado de forma vaga o início do ano letivo como data corte. Em 2010, por meio da Resolução $n^{\circ} .1 / 10$ (BRASIL, 2010a), ficou orientado que a criança deveria ter 6 anos de idade completos até o dia 31 de março do ano em que fosse ocorrer sua matrícula. De todo modo, a questão se manteve legalmente indefinida, permitindo variações nas datas corte dentro do contexto nacional.

Lima (2011) afirmou que, por conta dessa indefinição, durante muito tempo era possível encontrar em uma mesma sala de aula crianças de 5, 6 e até 7 anos de idade. Essa mistura de idades em uma turma também vai de encontro com o Parecer $n^{\circ} .4 / 08$, que destaca a necessidade de agrupar as crianças respeitando a faixa etária, rigorosamente.

Com isso, fica evidente que a política de ampliação do ensino fundamental para nove anos possui muitas lacunas e indefinições que impactaram na prática pedagógica das escolas. O fato de a estrutura e o funcionamento da política serem pautados, em sua maioria, em enunciados e orientações genéricas pode ter colaborado para que a proposta não tenha sido tão bem vista pelas escolas envolvidas nessas investigações. Além disso, o MEC/CNE/ CEB transferiu toda a responsabilidade de formação continuada e de adaptação estrutural e material para os próprios sistemas de ensino, que, conforme consta em boa parte das pesquisas estudadas, apenas receberam o aviso de que aconteceria a ampliação.

Ao relacionar e comparar o amparo oficial com as pesquisas sobre a prática do ensino fundamental de nove anos foi possível verificarmos muitas contradições, incertezas e inseguranças por parte de todos os profissionais que lidam com o cotidiano da escola. Também foi notável a presença de muito esforço individual por parte de cada escola e de cada professor para que o ensino fundamental de nove anos realmente se concretizasse, já que, como visto nas pesquisas, a formação continuada e preparação dos profissionais, de forma geral, deixou completamente a desejar.

Não obstante esses esforços individuais, que podem até ter apresentado bons resultados em determinados casos, ficou evidente que as escolas não conseguiram esclarecer todas as dúvidas sobre a política de ampliação do ensino fundamental para nove anos e, como consequência disso, houve divergências entre aquilo que ficou oficialmente proposto e aquilo que, ao que tudo indica, tem sido colocado em prática no dia a dia das escolas. 


\section{CONSIDERAÇõES FINAIS}

A ampliação do ensino fundamental para nove anos de duração, proposta incluída na educação brasileira desde o Plano Nacional de Educação de 2001, foi concretizada primeiramente em 2005, por meio da Lei $\mathrm{n}^{\circ}$. 11.114, que incluiu a criança de 6 anos de idade no ensino fundamental, e oficializada em 2006, com a Lei $\mathrm{n}^{\circ}$. 11.274 que efetivamente ampliou o ensino fundamental para nove anos, com a matrícula obrigatória da criança a partir dos 6 anos de idade. A última determinou, ainda, que as escolas tinham até o início do ano letivo de 2010 para se ajustarem a essa nova configuração.

Os pareceres e resoluções emitidos pelo Ministério da Educação não foram poucos, como visto, no total foram 14 textos entre os anos de 2004 e 2010. Isso demonstra que o processo legal de implantação do ensino fundamental de nove anos não aconteceu com transparência ou clareza, mas foi decorrente de muitas dúvidas por parte dos sistemas de ensino, que percorreu pelo menos seis anos de deliberações.

Esse fato mostra sua repercussão nas pesquisas voltadas para a prática do ensino fundamental de nove anos, que encontramos com a revisão bibliográfica. Os autores comprovaram que as dúvidas e incertezas dos sistemas de ensino impactaram no desenrolar da implementação do ensino fundamental de nove anos no cotidiano das escolas. Assim, na prática, restaram muitas dúvidas sobre o que fazer exatamente no $1^{\circ}$ ano e com as crianças de 6 anos de idade, sobre como reorganizar e interpretar o ensino fundamental de nove anos, acerca dos recursos humanos e administrativos para realização da proposta colocada pelo MEC, entre outras coisas.

Ao relacionarmos as pesquisas com o amparo legal constatamos, com ainda mais nitidez, o descompasso entre um e outro. A falta de descrição e pormenorização nos próprios documentos, bem como, o longo tempo que decorreu para a publicação de todos eles, acabou levando para as escolas urgências e necessidades da política de ampliação no ensino fundamental para nove anos. Com isso, as escolas, de forma geral, tiveram como saída o fazer espontâneo, de acordo com a intuição e a percepção de cada um de seus profissionais. Assim, apesar de existir uma legislação nacional sobre a referida política, as escolas de nove anos parecem estar funcionando conforme as interpretações pessoais dos professores e gestores.

Dessa maneira, notamos que a ampliação do ensino fundamental para nove anos, mesmo que tenha sido gestada por muito tempo dentro dos documentos oficiais e que tenha tido um longo percurso, com várias publicações do $\mathrm{MEC/CNE/CEB}$, chegou às escolas de forma súbita, como novo enigma a ser decifrado pelos agentes educacionais. Isso significa que seus benefícios para a educação brasileira ainda são incertos, já que questões importantes ficaram indefinidas, legadas aos critérios de escolha e de resolução de cada uma das localidades do país. 


\section{REFERÊNCIAS}

ABRAMOWICZ, Mere; SILVA, Viviane Aparecida. O currículo do novo primeiro ano do ensino fundamental e a participação infantil: o que acontece em sala de aula pode ser chamado de "novo"? Revista e-Curriculum, São Paulo, v. 13, nº. 3, p. 534-550 jul./set. 2015.

BRASIL. Lei no. 9.394, de 20 de dezembro de 1996. Estabelece as diretrizes e bases da educação nacional. Diário Oficial da União, Brasília, 23 de dez. 1996.

BRASIL. Lei $n^{\circ}$. 10.172, 9 de janeiro de 2001. Estabelece Plano Nacional de Educação. Diário Oficial da União, Brasília, 9 de jan. 2001.

BRASIL. CNE/CEB. Parecer n $n^{\circ}$. 24/2004, de 15 de setembro de 2004 (reexaminado pelo Parecer CNE/CEB $n^{\circ}$. 6/2005). Estudos visando ao estabelecimento de normas nacionais para a ampliação do Ensino Fundamental para nove anos de duração. Diário Oficial da União, Brasília, 2004a.

BRASIL. Lei ${ }^{\circ}$. 11.114, de 16 de maio de 2005. Altera a redação dos artigos 6, 30,32 e 87 da Lei $\mathrm{n}^{\circ}$. 9.394, de 20 de dezembro de 1996, com o objetivo de tornar obrigatório o início do ensino fundamental aos seis anos de idade. Diário Oficial da União, Brasília, 16 de maio, 2005a.

BRASIL. CNE/CEB. Parecer $n^{\circ}$. 06/2005, de 8 de junho de 2005. Reexame do Parecer $\mathrm{CNE} / \mathrm{CEB} \mathrm{n}^{\circ}$. 24/2004, que visa o estabelecimento de normas nacionais para a ampliação do Ensino Fundamental para nove anos de duração. Diário Oficial da União, Brasília, 2005 b.

BRASIL. CNE/CEB. Parecer $n^{\circ}$. 18/2005, de 15 de setembro de 2005. Orientações para a matrícula das crianças de seis anos de idade no Ensino Fundamental obrigatório, em atendimento à Lei $n^{\circ}$. 11.114/2005, que altera os arts. $6^{\circ}$., 32 e 87 da Lei no ${ }^{\circ}$ 9.394/96. Diário Oficial da União, Brasília, 2005c.

BRASIL. CNE/CEB. Resolução n ${ }^{\circ}$. 03/2005, de 3 de agosto de 2005. Define normas nacionais para a ampliação do Ensino Fundamental para nove anos de duração. Diário Oficial da União, Brasília, 2005d.

BRASIL. Lei $\mathrm{n}^{\circ}$. 11.274, de 6 de fevereiro de 2006. Altera a redação dos artigos 29, 30, 32 e 87 da Lei $\mathrm{n}^{\circ} .9 .394$, de 20 de dezembro de 1996, que estabelece as diretrizes e bases da educação nacional, dispondo sobre a duração de 9 (nove) anos para o ensino fundamental, com matrícula obrigatória a partir dos 6 (seis) anos de idade. Diário Oficial da União, Brasília, 7 de fev. 2006a. 
BRASIL. CNE/CEB. Parecer n ${ }^{\circ}$. 39/2006, de 8 de agosto de 2006. Consulta sobre situações relativas à matrícula de crianças de seis anos no Ensino Fundamental. Diário Oficial da União, Brasília, 2006b.

BRASIL. CNE/CEB. Parecer $n^{\circ}$. 41/2006, de 9 de agosto de 2006. Consulta sobre interpretação correta das alterações promovidas na Lei $\mathrm{n}^{\circ}$. 9.394/96 pelas recentes Leis $\mathrm{n}^{\circ}$. 11.114/2005 e nº 11.274/2006. Diário Oficial da União, Brasília, 2006c.

BRASIL. CNE/CEB. Parecer $n^{\circ}$. 45/2006, de 7 de dezembro de 2006. Consulta referente à interpretação da Lei Federal nº 11.274 , de 6/2/2006, que amplia a duração do Ensino Fundamental para nove anos, e quanto à forma de trabalhar nas séries iniciais do Ensino Fundamental. Diário Oficial da União, Brasília, 2006d.

BRASIL. CNE/CEB. Parecer $n^{\circ}$. 05/2007, de $1^{\circ}$. de fevereiro de 2007 (reexaminado pelo Parecer CNE/CEB no. 7/2007). Consulta com base nas Leis $n^{\circ} .11 .114 / 2005$ e $n^{\circ}$. 11.274/2006, que tratam do Ensino Fundamental de nove anos e da matrícula obrigatória de crianças de seis anos no Ensino Fundamental. Diário Oficial da União, Brasília, 2007a.

BRASIL. CNE/CEB. Parecer $n^{\circ}$. 07/2007, de 19 de abril de 2007. Reexame do Parecer CNE/CEB $n^{\circ}$. 5/2007, que trata da consulta com base nas Leis $n^{\circ}$. 11.114/2005 e $\mathrm{n}^{\circ}$. 1.274/2006, que se referem ao Ensino Fundamental de nove anos e à matrícula obrigatória de crianças de seis anos no Ensino Fundamental. Diário Oficial da União, Brasília, 2007b.

BRASIL. CNE/CEB. Parecer nº 04/2008, de 20 de fevereiro de 2008. Orientação sobre os três anos iniciais do Ensino Fundamental de nove anos. Diário Oficial da União, Brasília, 2008.

BRASIL. CNE/CEB. Parecer $n^{\circ}$. 22/2009, de 9 de dezembro de 2009. Diretrizes operacionais para a implantação do Ensino Fundamental de 9 (nove) anos. Diário Oficial da União, Brasília, 2009a.

BRASIL. CNE/CEB. Resolução ${ }^{\circ}$. 01/2010, de 14 de janeiro de 2010. Define diretrizes operacionais para a implantação do Ensino Fundamental de 9 (nove) anos. Diário Oficial da União, Brasília, 2010a.

BRASIL. CNE/CEB. Parecer no. 11, de 7 de julho de 2010. Diretrizes Curriculares Nacionais para o Ensino Fundamental de 9 (nove) anos. Diário Oficial da União, Brasília, 2010 b.

BRASIL. CNE/CEB. Resolução no. 07/2010, de 14 de dezembro de 2010. Fixa Diretrizes Curriculares Nacionais para o Ensino Fundamental de 9 (nove) anos. Diário Oficial da União, Brasília, 2010c. 
DURLI, Zenilde; SCHNEIDER, Marilda Pasqual. Ampliação do ensino fundamental na região sul do Brasil: pontos e contrapontos da proposta curricular. Educação em Revista, Belo Horizonte, v. 31, nº. 1, p. 223-247, jan./mar. 2015.

GIL, Lara Gonzalez. Implementação de Políticas Públicas: um estudo de caso sobre a ampliação do ensino fundamental para nove anos no município de São Bernardo do Campo, 2012, 233p. Dissertação (Mestrado em Educação), Universidade de São Paulo, Faculdade de Educação, São Paulo, 2012.

KLEIN, Sylvie Bonifácio. Ensino fundamental de nove anos no município de São Paulo: um estudo de caso, 2011, 233p. Dissertação (Mestrado em Educação), Universidade de São Paulo, Faculdade de Educação, São Paulo, 2011.

LIMA, Lilian Aparecida. Ensino fundamental de nove anos: repercussões da Lei ${ }^{\circ}$. 11.274/2006 na proposta curricular da rede municipal de ensino de Juiz de Fora, 2011, 208s. Dissertação (Mestrado em Educação) Universidade Federal de Juiz de Fora, Juiz de Fora, 2011.

MACHADO, Rosangela Aparecida dos Reis. A implementação do ensino fundamental de nove anos na rede municipal de ensino de São Paulo, 2016, 164s. Tese (Doutorado em Educação), Universidade Nove de Julho - UNINOVE, São Paulo, 2016.

NOGUEIRA, Gabriela Medeiros; PERES, Eliane Teresinha. A supremacia da perspectiva associacionista em práticas alfabetizadoras no $1^{\circ}$ ano do ensino fundamental de nove anos. Educação em Revista, Belo Horizonte, v. 29, nº 2, p. 65-89, jun. 2013.

OLIVEIRA, Selma Ferreira de. Implantação da política do ensino fundamental de nove anos: um estudo com grupos focais de professores, 2013, 133s. Tese (Doutorado em Educação), Universidade Estadual Paulista, Faculdade de Filosofia e Ciências, Marília, 2013.

PANSINI, Flávia; MARIN, Aline Paula. O ingresso de crianças de 6 anos no ensino fundamental: uma pesquisa em Rondônia. Educação e Pesquisa. São Paulo, v. 37, nº 1, 220p., 87-103, jan./abr. 2011.

PUGLIESE, Ebe Camargo. Implantação do ensino fundamental de nove anos e mudança educacional: estudo de duas experiências no município de Taubaté/SP. 2016, 237p. Dissertação (Mestrado em Educação), Universidade de São Paulo, Faculdade de Educação, São Paulo, 2016.

SALERNO, Soraia Kfouri; FULCHINI, Alzeni de Jesus Correia. Ensino fundamental de nove anos - ampliação ou absorção? A experiência do município de Londrina. Interfaces da Educação, Paranaíba, v. 4, nº 11, p. 57-71, 2013. 


\section{Dados das AUTORAs:}

\section{Jaqueline Cristina da Silva}

Mestranda pelo Programa de Pós-Graduação em Educação da Universidade Federal De São Carlos. São Carlos/SP - Brasil. jaquelinecristina011@gmail.com

\section{Géssica Priscila Ramo}

Doutora em Educação pela Universidade Federal de São Carlos. Professora associada da Universidade Federal de São Carlos e professora integrante do Programa de Pós-Graduação em Educação desta instituição. São Carlos/SP - Brasil. gessicaramos@ufscar.br

Submetido em: 2-3-2018

Aceito em: 12-2-2019 